\title{
Correction to: Efficient Preparation of Blast Furnace Burdens from Titanomagnetite Concentrate by Composite Agglomeration Process
}

\author{
TAO JIANG, ${ }_{1}^{1}$ LIANGPING XU, ${ }^{1}$ QIANG ZHONG ${ }^{10},{ }^{1,2}$ CHEN LIU, ${ }^{1}$ \\ HUIBO LIU, ${ }^{1}$ MINGJUN RAO, ${ }^{1}$ ZHIWEI PENG, ${ }^{1}$ and GUANGHUI LI ${ }^{1}$ \\ 1.-School of Minerals Processing and Bioengineering, Central South \\ University, Changsha 410083, Hunan, China. 2.-e-mail: zhongqiang@csu.edu.cn
}

\section{Correction to:}

JOM, Vol. 73, No. 1, 2021, p. 326,

https://doi.org/10.1007/s11837-020-04480-2

This article was updated to correct the duplication of part $b$ in Figure 2. 

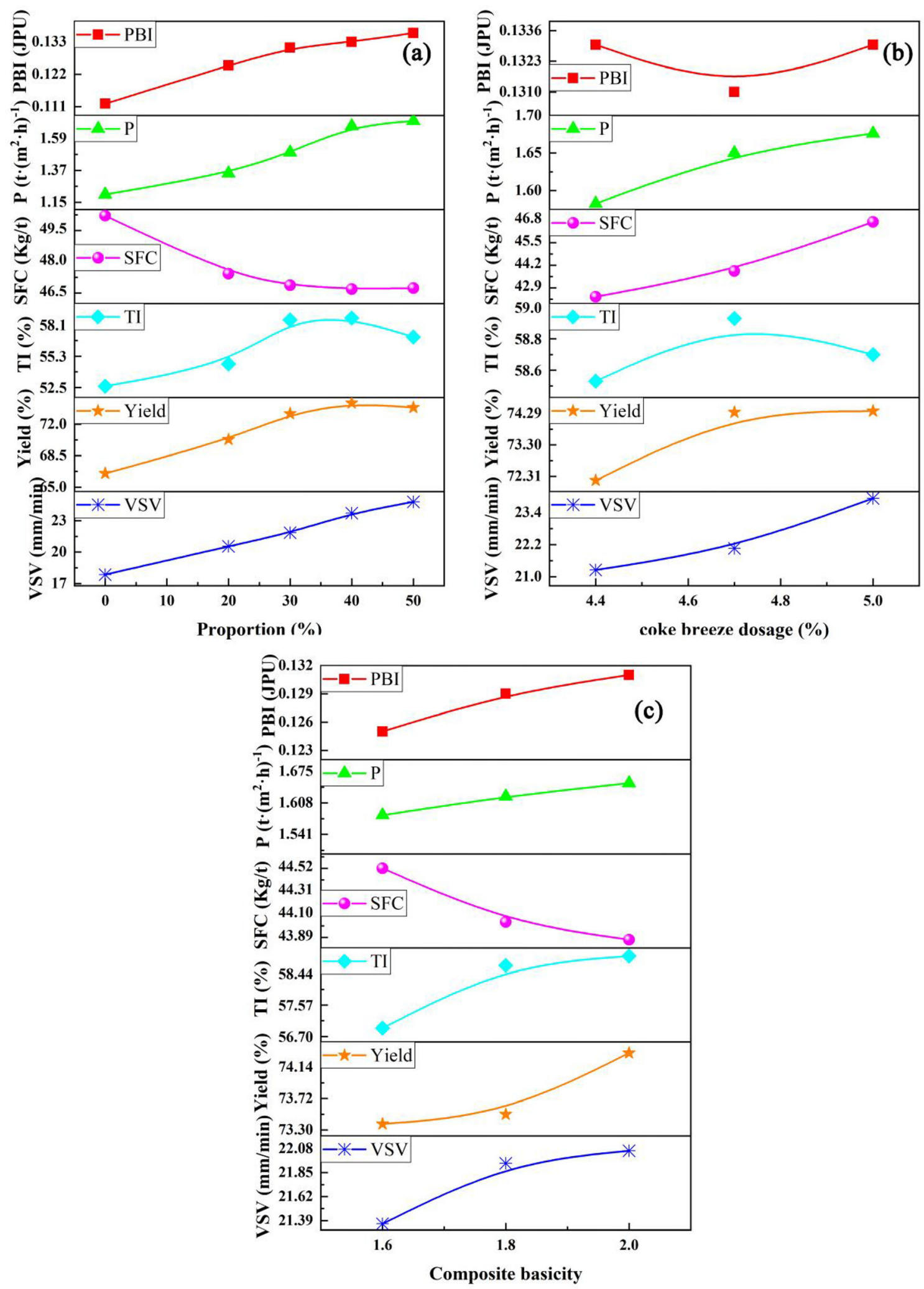

Fig. 2. Effect of process conditions on the agglomeration indexes of CAP (a) pelletized feed proportion, (b) coke breeze dosage, (c) composite.

Publisher's Note Springer Nature remains neutral with regard to jurisdictional claims in published maps and institutional affiliations. 